\title{
Approach to Empyema Necessitatis
}

\author{
Philip T. Peverada
}

Published online: 18 March 2011

(C) Société Internationale de Chirurgie 2011

Tuberculous empyema and empyema necessitatis are entities that have been familiar to physicians for millennia. Hippocrates described the condition along with signs, symptoms, physical findings and treatment over 2000 years ago [1]. Without the aid of CT scans, ultrasound or modern surgical techniques, he and his students were able to treat empyema with some success. In the non-tubercular world of parapneumonic effusions, successful treatment awaited Graham and Bell's studies as members of the Empyema Commission with the understanding of open pneumothorax, water seal, and pleural fusion [2, 3]. Physicians have been successfully treating empyema for years, so current practitioners have no stranglehold on the accumulated knowledge of this disease.

The article by Akgul et al. in the current issue of World Journal of Surgery presents a "modern" approach to the problem of a neglected tuberculous empyema [4]. This is an entity not often seen in modern clinical practice, so it is good to review the basics of treatment as these authors have.. When the patient is frail, old, and sick, simple drainage as advocated by our Greek forefathers is effective and still the treatment of choice today. In the healthier, younger, nutritionally sound patient, a formal decortication will result in quicker recovery and healing, a luxury we in the twenty-first century can enjoy, having become used to instant gratification. We have many resources at our disposal for imaging and localization, but our forebears did a remarkable job with examination, mustard plasters, and hot pokers.

P. T. Peverada $(\bowtie)$

Department of Surgery, Eastern Maine Medical Center,

Bangor, ME 04444, USA

e-mail: ppeverada@emh.org
The conundrum of how to approach the parapneumonic effusion extends beyond tuberculosis. In today's society the expectation is of a benign and swift hospitalization with rapid resumption of normal activities. Avoidance of a thoracotomy by way of thoracoscopy has increased the pressure on the surgeon to intervene early, sometimes defying the natural history of the disease process. Akgul and co-authors have offered us an approach to severe infections, but we are still awaiting a similar review of the operative indications for less severe parapneumonic effusions in community-acquired pneumonias. It would seem that in this group of patients, thoracoscopy, like its cousin, laparoscopy, has an appeal that perhaps outweighs its usefulness. Unfortunately, research such as that of Graham and Bell and controlled studies can be difficult to conduct, leaving us to depend on anecdotes and accumulated experience.

We applaud the meld of old and new advocated by the authors and salute the giants upon which these techniques are based.

\section{References}

1. Somers J, Faber LP (1996) Historical developments in the management of empyema. Chest Surg Clin North Am 6:403

2. Graham EA, Bell RD (1918) Open pneumothorax: its relation to the treatment of empyema. Am J Med Sci 156:839

3. Aboud FC, Verghese AC (2002) Evarts Ambrose Graham, empyema, and the dawn of clinical understanding of negative intrapleural pressure. Clin Infect Dis 34:198

4. Akgül AG, Örki A, Örki T et al (2011) Approach to empyema necessitatis. World J Surg. doi:10.1007/s00268-011-1035-5 